\title{
BMJ Open Predictive value of heart rate in patients with acute type A aortic dissection: a retrospective cohort study
}

\author{
Yong Zhou, ${ }^{1}$ Qipeng Luo, ${ }^{2}$ Xiaoxiao Guo, ${ }^{3}$ Hongbai Wang, ${ }^{1}$ Yuan Jia, ${ }^{1}$ Liang Cao, ${ }^{1}$ \\ Yang Wang, ${ }^{4}$ Fuxia Yan, ${ }^{1}$ Cuntao $\mathrm{Yu},{ }^{5}$ Su Yuan (i) ${ }^{1}$
}

To cite: Zhou Y, Luo Q, Guo X, et al. Predictive value of heart rate in patients with acute type $A$ aortic dissection: a retrospective cohort study. BMJ Open 2021;11:e047221. doi:10.1136/ bmjopen-2020-047221

- Prepublication history and additional supplemental material for this paper are available online. To view these files, please visit the journal online (http://dx.doi.org/10.1136/ bmjopen-2020-047221)

YZ, QL and XG contributed equally.

Received 07 December 2020 Accepted 25 October 202

Check for updates

(c) Author(s) (or their employer(s)) 2021. Re-use permitted under CC BY-NC. No commercial re-use. See rights and permissions. Published by BMJ.

For numbered affiliations see end of article.

Correspondence to

Dr Su Yuan;

fuwaiys@126.com and

Dr Cuntao Yu;

fuwaiyct@126.com

\section{ABSTRACT}

Objective Heart rate $(\mathrm{HR})$ is a risk factor of mortality in many cardiovascular diseases but no clinical studies have focused on the association between HR and prognosis in patients with acute type A aortic dissection (ATAAD). This study aimed to evaluate the association between $\mathrm{HR}$ and long-term mortality and establish the criteria of $\mathrm{HR}$ in patients with ATAAD who underwent total aortic arch replacement combined with the frozen elephant trunk (TAR+FET).

Design, setting and participants Retrospective cohort study that studied all consecutive patients with ATAAD who underwent TAR+FET in the Fuwai Hospital between 2009 and 2015.

Main outcomes and measures 30-day postoperative, and estimated long-term mortality.

Results Overall, 707 patients with ATAAD who underwent TAR+FET were followed up for a median duration of 29 months (range, 5-77 months). In multivariate logistic analysis, $H R(p<0.001)$, age $(p<0.001)$, renal insufficiency $(p=0.033)$, ejection fraction $(p=0.005)$, cardiopulmonary bypass time $(p<0.001)$ and intraoperative blood loss $(p=0.002)$ were significantly associated with 30 -day postoperative and estimated long-term mortalities. A hinge point with a sharp increase in estimated longterm mortality was identified at 80 beats/min (bpm), and compared with $\mathrm{HR} \leq 80 \mathrm{bpm}, \mathrm{HR}>80 \mathrm{bpm}$ was associated with an almost threefold higher long-term mortality. HRs $\leq 60,60-70,70-80,80-90,90-100,100-110$ and $>110$ bpm were associated with $3.9 \%, 4.0 \%, 3.8 \%, 7.2 \%, 9.5 \%$, $10.1 \%$ and $14.4 \%$ yearly risks of death, respectively. Conclusions HR is a powerful predictor of long-term mortality in patients with ATAAD undergoing TAR+FET. $\mathrm{HR}>80 \mathrm{bpm}$ is independently associated with elevated long-term mortality for patients with ATAAD.

\section{INTRODUCTION}

Many studies have demonstrated that heart rate (HR) is a risk factor of mortality in many cardiovascular diseases, ${ }^{1-5}$ including type $\mathrm{B}$ aortic dissection. ${ }^{6-8}$ However, to the best of our knowledge, no clinical studies have focused on the association between HR and long-term prognosis in patients with acute type A aortic dissection (ATAAD) who underwent total aortic arch replacement combined with the frozen elephant trunk (TAR+FET).

\section{Strengths and limitations of this study}

- First study to systematically evaluate the association between heart rate (HR) and long-term mortality in patient with acute type $A$ aortic dissection (ATAAD).

- The importance of HR in short-term and long-term mortality was evaluated and a hinge point $\mathrm{HR}$ in patients with ATAAD was recommended.

- Convenient prediction tool based on preoperative risk factors was created to calculate the probability of long-term mortality.

- Did not include patients who did not undergo surgery or died before arriving in the operating room and the retrospective and observational nature of the study might bring confounding and bias. Did not consider preoperative treatment and therefore unable to decide whether preoperative HR control would improve long-term mortality.

Because of the urgency and fatalness of ATAAD, all of the current guidelines ${ }^{9-12}$ highlight the importance of emergency surgery and blood pressure control. Most guidelines do not recommend a target HR in patients with ATAAD. Although the use of betablockers is suggested in all these guidelines, beta-blockers were mainly used for blood pressure control and reduction in $\mathrm{dP} / \mathrm{dt}$ and not for HR reduction. In the 2011 Japanese Circulation Society guidelines, ${ }^{10}$ pulse rate control is recommended as one of the most important aspects of treatment in acute aortic dissection, whereas no specific target of HR is suggested. Only the 2010 American College of Cardiology Foundation/American Heart Association guidelines ${ }^{9}$ recommend titrating to a target HR of $60 \mathrm{bpm}$ or less (class I, level of evidence: $\mathrm{C}$ ). However, this was referenced only in a review published in $2005,{ }^{13}$ and the review did not provide any relevant clinical trials. Similarly, Nienaber and Powell ${ }^{14}$ suggested a target HR of $60-80 \mathrm{bpm}$ as the initial medical therapy for acute aortic syndromes in a review published in 2011, and they did not provide any relevant clinical 
Table 1 Patient characteristics

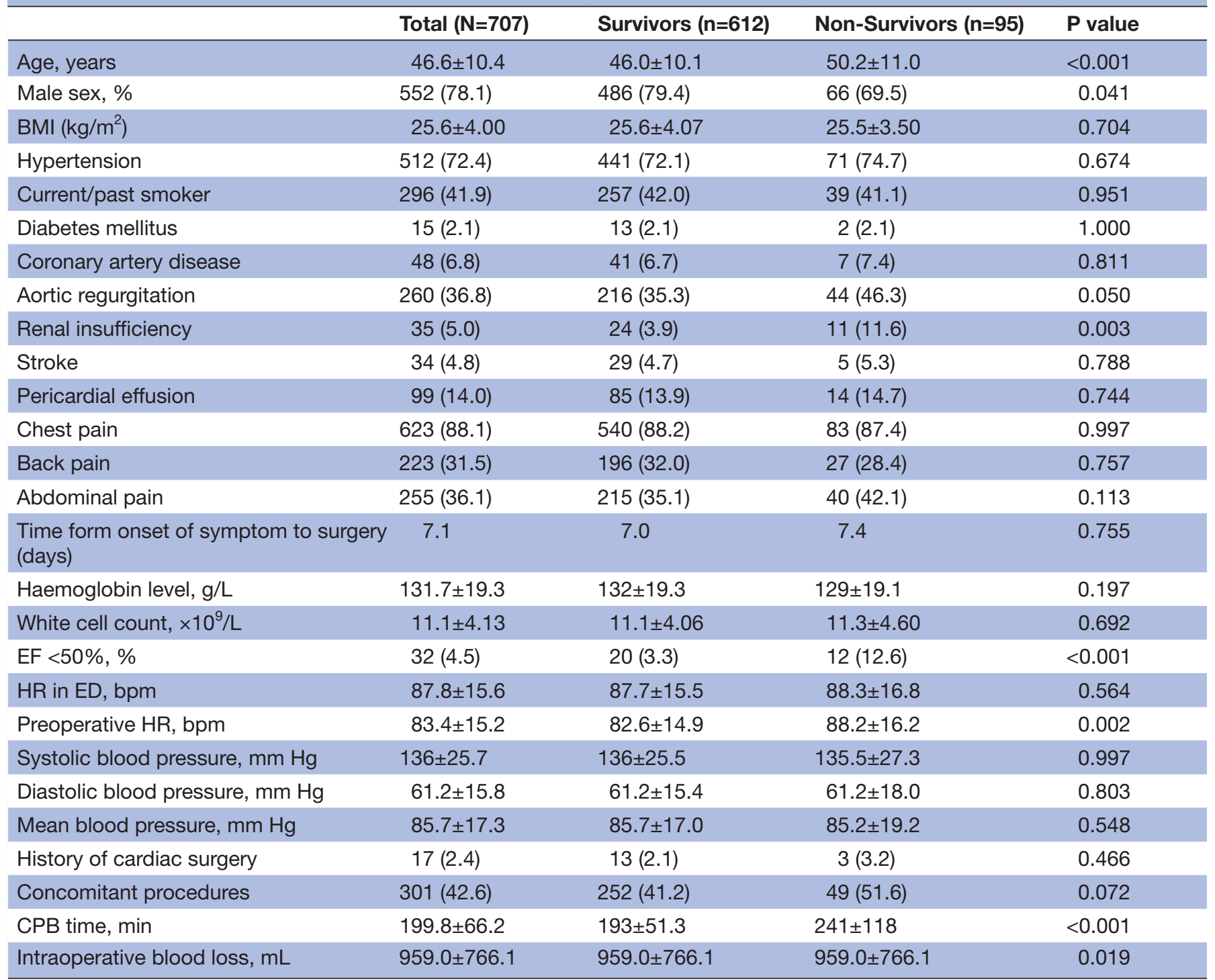

Values are expressed as mean \pm SD or $\mathrm{n}(\%)$, as appropriate.

$\mathrm{BMI}$, body mass index; bpm, beats/min; CPB, cardiopulmonary by pass; ED, emergency department; EF, ejection fraction; HR, heart rate.

trials as well. Therefore, this study aimed to evaluate the association between HR and long-term all-cause mortality and explore the hinge point of HR among patients with ATAAD who underwent TAR+FET.

\section{METHODS}

\section{Patients and data collection}

After receiving approval from the Ethics Committees of Fuwai Hospital in Beijing, China, and under a waiver of informed consent, the authors conducted this retrospective observational study of all consecutive patients with ATAAD who underwent TAR+FET between December 2009 and December 2015. ATAAD was defined by observing an intimal flap separating two lumina in the ascending aorta that occurred within 14 days of symptom onset. ${ }^{15}$ The TAR+FET surgical technique has been described previously in detail and is viewed as a standard therapy for ATAAD requiring repair of the aortic arch. ${ }^{16}$ Patients were monitored using electrocardiography, pulse oximetry and the Intellivue MX700 monitor (Philips, Amsterdam, the Netherlands) (left radial and dorsalis pedis arterial pressures) in the operating room. Data related to demographic and in-hospital clinical variables were retrospectively collected from medical charts and electronic medical records, and patients were followed up by telephone and outpatient review.

HR was recorded every 5 min when a patient arrived in the operating room and the average of the first three values of HRs before anaesthesia induction was used in our study from electronic medical records. Long-term mortality was defined as 5-year postoperative mortality. Blood pressure was defined as the higher values between radial and dorsalis pedis pressure before anaesthesia 
Table 2 Models for estimated long-term mortality

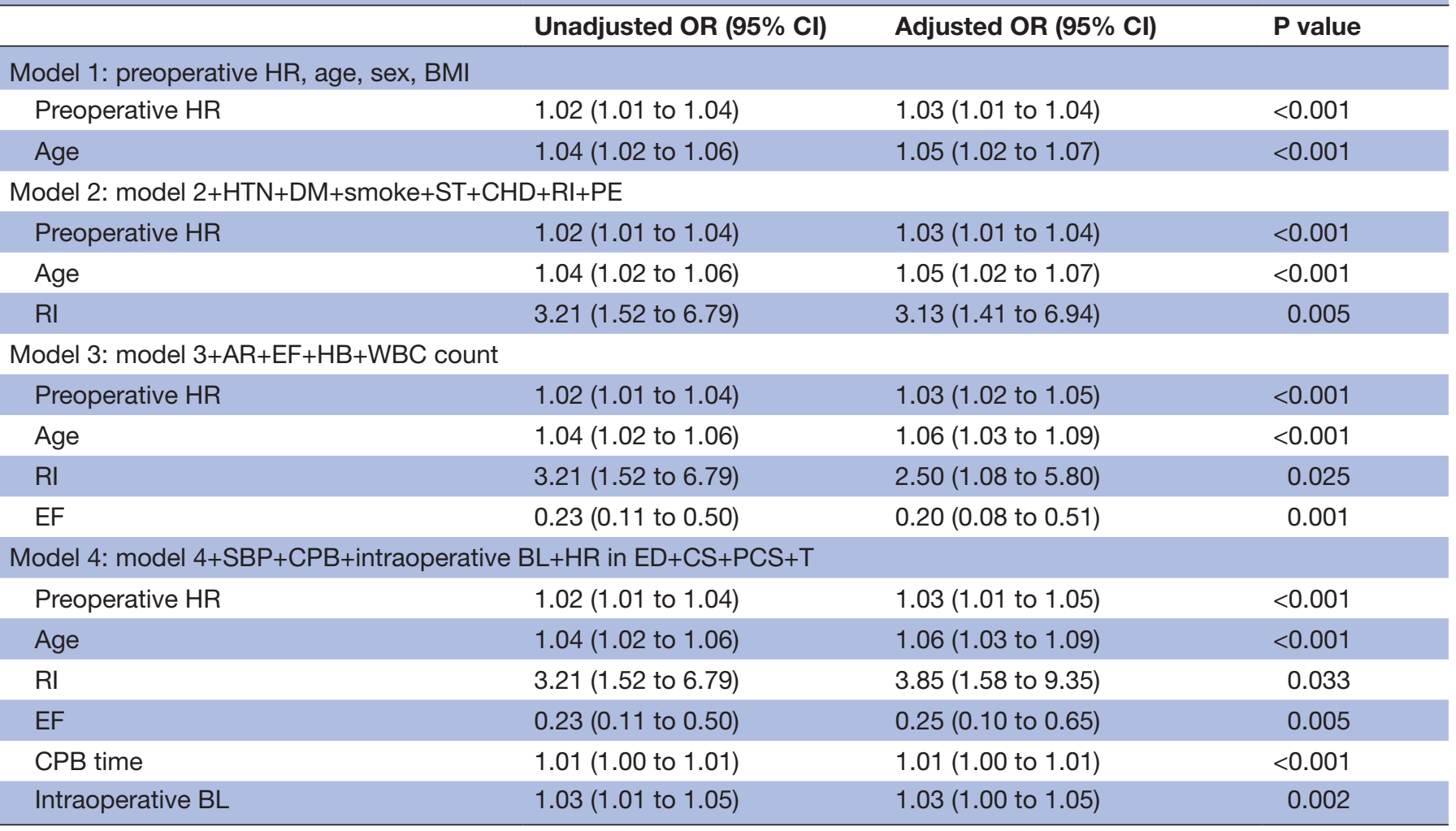

$\mathrm{AR}$, moderate to severe aortic regurgitation; BL, blood loss; BMI, body mass index; CHD, coronary heart disease; CPB, cardiopulmonary bypass; CS, concomitant surgery; DM, diabetes mellitus; ED, emergency department; EF, ejection fraction; HB, haemoglobin; HR, heart rate; HTN, hypertension; PCS, prior cardiac surgery; PE, pericardial effusion; RI, renal insufficiency; SBP, systolic blood pressure; ST, stroke; T, time from onset of symptom to surgery; WBC, white blood cell.

induction (according to systolic blood pressure (SBP)). The four-variable Modification of Diet in Renal Disease equation was used to calculate the estimated glomerular

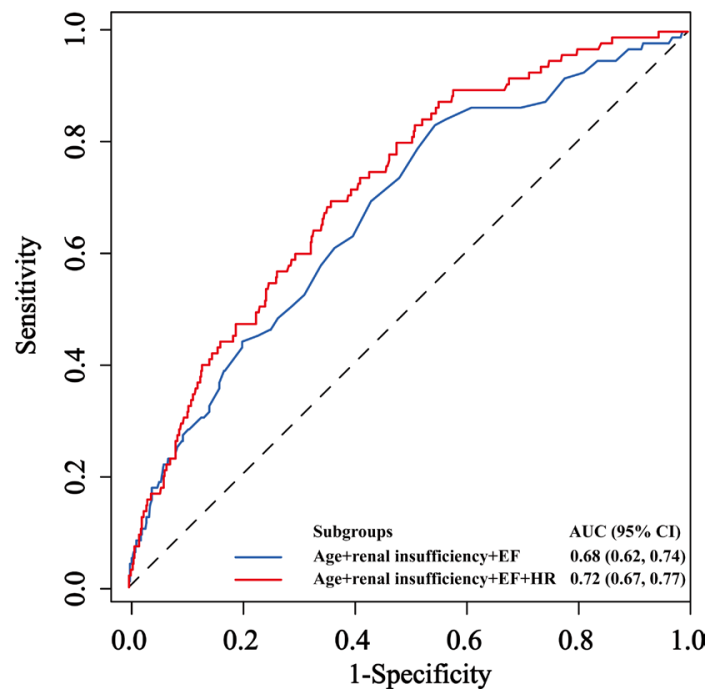

Figure 1 Receiver operating characteristic curve for multivariate logistic regression analysis. There is a significant improvement in the discrimination of the logistic regression model by introducing preoperative HR (an increase in AUC of $0.04, p=0.024)$. AUC, area under the receiver operating characteristic curve; EF, ejection fraction; HR, heart rate. filtration rate. ${ }^{17}$ Renal insufficiency (RI) was defined as the preoperative estimated glomerular filtration rate $<90 \mathrm{~mL} / \mathrm{min}$ or dialysis.

\section{Statistical analysis}

Values are expressed as mean $\pm \mathrm{SD}$ or number of patients $(\%)$, as appropriate. Multivariate logistic regression models were used to identify independent predictors of long-term mortality. To minimise selection bias and obtain comparable groups, propensity score matching (PSM) analysis was used to confirm the association between HR and long-term mortality. PSM of 1:1 ratio and 0.20 calliper by the 'nearest neighbour' method was performed with the 'Matching' package. The area under the receiver operating characteristic curve (AUC) was used to assess the discriminative performance of the logistic regression model. The long-term survival rate was analysed using the Kaplan-Meier analytical method and Cox regression analysis. The predictive models were built using the average of the predicted 5-year risk from the Cox proportional hazard model via the 'coxph' function of the 'survival' package in the R software package (R Foundation for Statistical Computing, Vienna, Austria). The Kaplan-Meir survival analyses were visualised using 'survminer' and 'ggplot2' packages in the $\mathrm{R}$ software package. The $\mathrm{R}$ software package, 


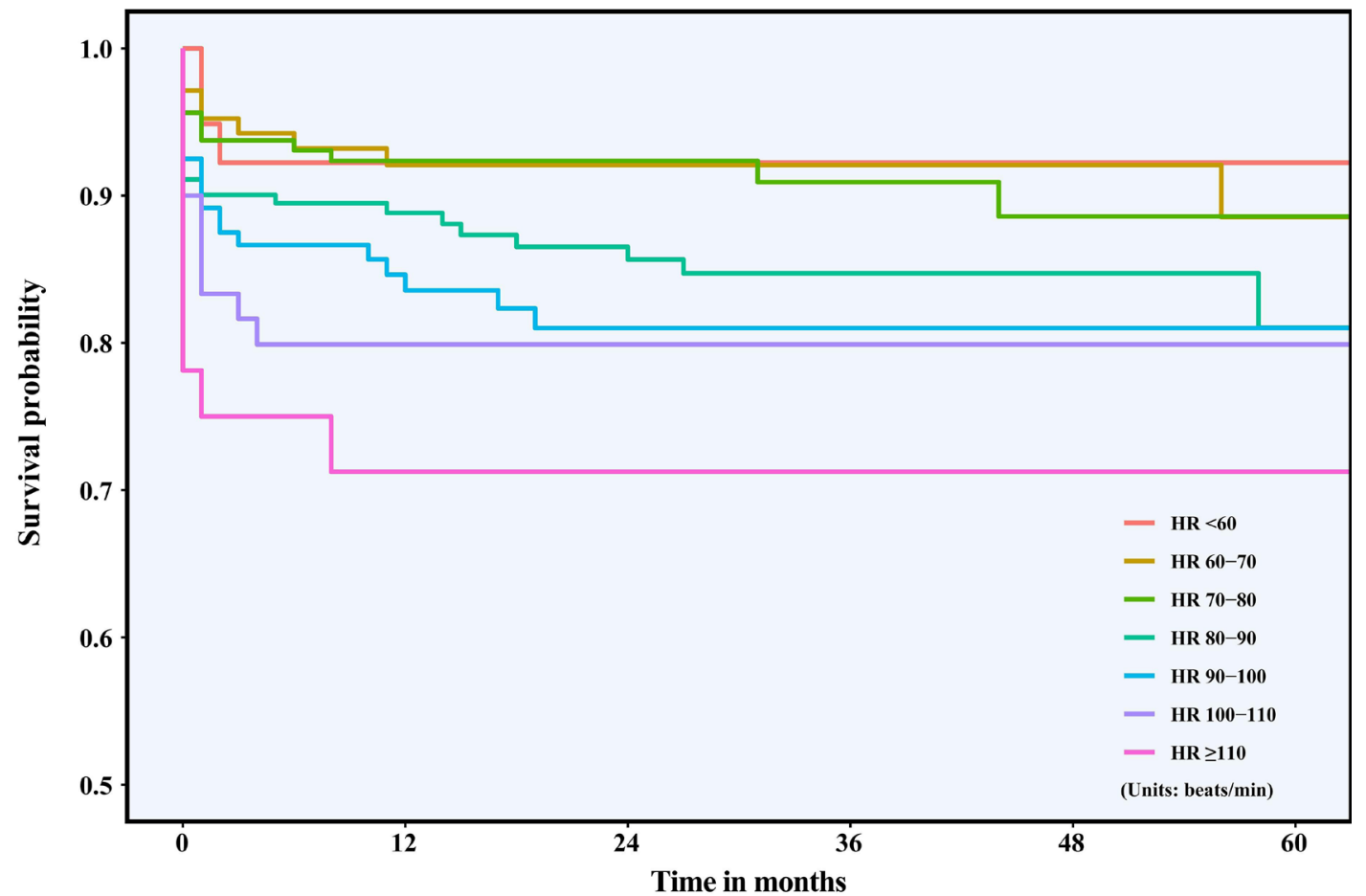

\begin{tabular}{|c|c|c|c|c|c|c|}
\hline \multirow[b]{2}{*}{$\mathrm{HR}<60$} & \multicolumn{6}{|c|}{ Number at risk: $\mathrm{n}(\%)$} \\
\hline & $39(100)$ & $27(69)$ & $20(51)$ & $15(38)$ & $11(28)$ & $6(15)$ \\
\hline HR 60-70 & $105(100)$ & $81(77)$ & 69 (66) & $48(46)$ & $32(30)$ & $21(20)$ \\
\hline HR 70-80 & $160(100)$ & $115(72)$ & $82(51)$ & $55(34)$ & $33(21)$ & $19(12)$ \\
\hline HR 80-90 & $191(100)$ & $129(68)$ & $100(52)$ & $67(35)$ & $40(21)$ & $17(9)$ \\
\hline HR 90-100 & $120(100)$ & $79(66)$ & $58(48)$ & $35(29)$ & $28(23)$ & $12(10)$ \\
\hline HR 100-110 & $60(100)$ & $40(67)$ & $31(52)$ & $18(30)$ & $10(17)$ & $4(7)$ \\
\hline$H R \geq 110$ & $32(100)$ & $19(59)$ & $15(47)$ & $13(41)$ & $8(25)$ & $3(9)$ \\
\hline (Units: beats/mir & 0 & 12 & 24 & 36 & 48 & 60 \\
\hline
\end{tabular}

Figure 2 Kaplan-Meier analysis according to different HRs. Increased HR is significantly associated with a lower cumulative survival rate than decreased HR. A 5 beats/min increment of HR is associated with an $11.8 \%$ increased risk of all-cause mortality in the univariate Cox regression analysis. Additional adjustment for other variables did not change the significance of the association. HR, heart rate.

V.3.5.1 was used to analyse the data, and GraphPad Prism V.7.00 for Windows (GraphPad Software, San Diego, California, USA) was used for data analysis and visualisation. A two-tailed $\mathrm{p}$ value $<0.05$ was considered statistically significant.

\section{Patient and public involvement}

Patients or the public were not involved in the design, or conduct, or reporting, or dissemination plans of our research.

\section{RESULTS}

\section{Clinical features and surgical data}

From December 2009 to December 2015, 960 patients with ATAAD had surgeries in the Fuwai Hospital (online supplemental table 1). Of which, 746 patients underwent TAR+FET. After excluding, 39 of them for failure of follow-up, 707 patients were enrolled in this study. The clinical characteristics of the 707 patients are shown in table 1. Concomitant procedures included aortic valve repair in 22 patients, aortic root replacement in 227 patients, mitral valve operations in 9 patients, and coronary artery bypass grafting in 76 patients. Patients' mean age was $46.6 \pm 10.4$ years, and male sex was predominant $(78 \%)$. During a median follow-up of 29 months (range, 5-77 months) 95 patients died.

\section{Association between HR and estimated long-term mortality}

In the multivariate logistic regression analysis, HR $(\mathrm{p}<0.001)$, age $(\mathrm{p}<0.001)$, RI $(\mathrm{p}=0.033)$, ejection fraction (EF) $(\mathrm{p}=0.005)$, cardiopulmonary bypass time $(p<0.001)$ and intraoperative blood loss $(p=0.002)$ were identified as independent predictors of estimated long-term all-cause mortality. After adjusting for the 

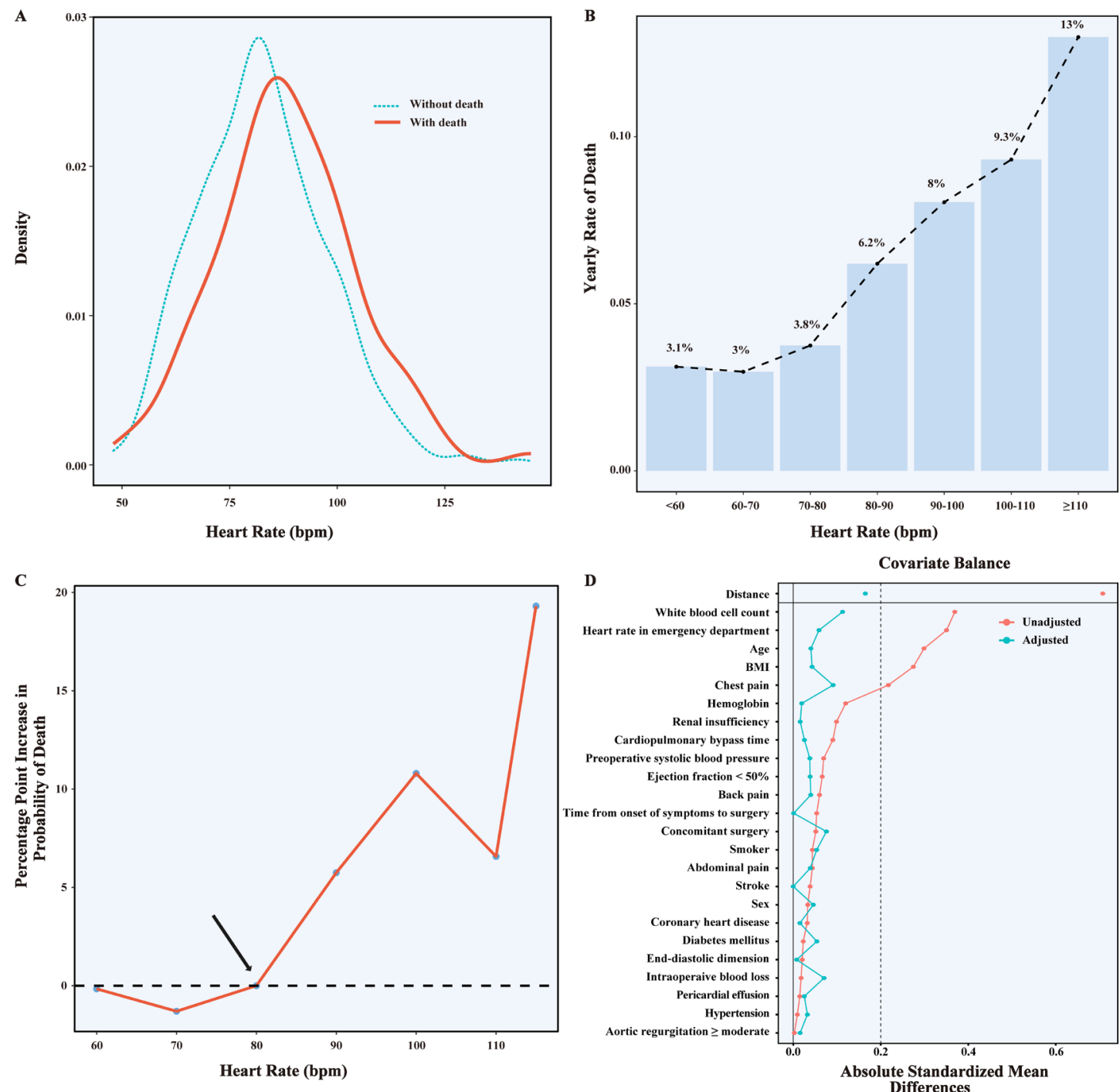

Figure 3 (A) Kernel density plots showing the distribution of HR. (B) Long-term mortality rates increase with increased HR. (C) Hinge plot. A cut-off HR of $80 \mathrm{bpm}$ is observed and a sharp increase of estimated probability of long-term death occurs when $\mathrm{HR}>80 \mathrm{bpm}$. (D) Love plot showing absolute standardised differences before (red) and after (green) PSM comparing covariate values. BMI, body mass index; bpm, beats/min; HR, heart rate; PSM, propensity score matching.

demographic data, history of cardiac surgery and preoperative tests results, the above-mentioned six variables remained independently associated with long-term allcause mortality (table 2). When we replaced SBP with diastolic blood pressure or mean blood pressure, the results were similar. There was a significant improvement in the discrimination of the logistic regression model by introducing HR (an increase in AUC of 0.04, $\mathrm{p}=0.024$; figure 1). According to the Kaplan-Mieier curves, increased HR was significantly associated with lower cumulative survival rate than lower HR (figure 2). In addition, a 5-bpm increment of HR was associated with an $11.8 \%$ increased risk of all-cause mortality in the univariate Cox regression analysis, and additional adjustment for other variables did not change the significance of the association. However, we failed to find a significant relationship between heart rate in emergency department (defined as the heart rate from the first electrocardiograph when a patient arrived in emergency department) and long-term mortality.

\section{Risk stratification based on HR}

As illustrated in figure 3A, a significant 'rightward shift' of HR was observed in the long-term non-survivor group compared with that in the long-term survivor group $(\mathrm{p}<0.001)$. The long-term survival, estimated using Kaplan-Meier analysis as a function of preoperative HR, is shown in figure 2 . HRs $\leq 60,60-70,70-80,80-90,90-100$, $100-110$ and $>110 \mathrm{bpm}$ were associated with a $3.9 \%, 4.0 \%$, $3.8 \%, 7.2 \%, 9.5 \%, 10.1 \%$ and $14.4 \%$ yearly risk of death, respectively, which suggest that the risk of death sharply increased when HR $>80 \mathrm{bpm}$.

To confirm an appropriate cut-off value of HR for risk prediction, a hinge point (HR of $80 \mathrm{bpm}$ ) was observed, that is, a sharp increase in the estimated probability of longterm death occurred when HR $>80 \mathrm{bpm}$ (figure 3B,C). 
Table 3 Outcomes of propensity score matching

\begin{tabular}{|c|c|c|c|c|c|c|}
\hline & \multicolumn{3}{|l|}{ Before matched } & \multicolumn{3}{|c|}{ After matched } \\
\hline & $H R \leq 80(n=304)$ & $\begin{array}{l}H R>80 \\
(n=403)\end{array}$ & $P$ value & $\begin{array}{l}\mathrm{HR} \leq 80 \\
(\mathrm{n}=266)\end{array}$ & $\begin{array}{l}\mathrm{HR}>80 \\
(\mathrm{n}=266)\end{array}$ & $P$ value \\
\hline WBC, $\times 10^{9}$ & $10.2 \pm 3.74$ & $11.8 \pm 4.28$ & $<0.001$ & $10.6 \pm 3.76$ & $11.1 \pm 4.15$ & 0.238 \\
\hline Heart rate in ED & $84.5 \pm 14.6$ & $90.1 \pm 16.0$ & $<0.001$ & $85.8 \pm 14.5$ & $86.7 \pm 14.5$ & 0.281 \\
\hline Age & $48.3 \pm 10.6$ & $45.3 \pm 9.98$ & $<0.001$ & $47.1 \pm 10.4$ & $46.7 \pm 9.97$ & 0.699 \\
\hline $\mathrm{BMI}, \mathrm{kg} / \mathrm{m}^{2}$ & $25.0 \pm 3.85$ & $26.1 \pm 4.05$ & $<0.001$ & $25.2 \pm 3.92$ & $25.4 \pm 3.61$ & 0.510 \\
\hline Chest pain & $257(84.5)$ & $366(90.8)$ & 0.0175 & $233(87.6)$ & $240(90.2)$ & 0.392 \\
\hline Haemoglobin, g/L & $130 \pm 18.9$ & $133 \pm 19.6$ & 0.0522 & $131 \pm 19.2$ & $131 \pm 19.7$ & 0.674 \\
\hline Renal insufficiency & $11(3.6)$ & $24(6.0)$ & 0.169 & $10(3.8)$ & $11(4.1)$ & 0.990 \\
\hline CPB time & $196 \pm 57.2$ & $203 \pm 72.1$ & 0.369 & $197 \pm 58.8$ & $199 \pm 66.3$ & 0.981 \\
\hline Preoperative SBP & $138 \pm 26.3$ & $137 \pm 27.3$ & 0.941 & $138 \pm 26.9$ & $135 \pm 26.8$ & 0.385 \\
\hline $\mathrm{EF}<50 \%$ & $16(5.3)$ & $16(4.0)$ & 0.488 & $14(5.3)$ & $12(4.5)$ & 0.850 \\
\hline Back pain & 91 (29.9) & $132(32.8)$ & 0.466 & $82(30.8)$ & 87 (32.7) & 0.693 \\
\hline $\begin{array}{l}\text { Time from onset of symptom } \\
\text { to surgery, days }\end{array}$ & $7.76 \pm 8.63$ & $7.28 \pm 9.11$ & 0.188 & $7.65 \pm 8.73$ & $7.65 \pm 9.86$ & 0.434 \\
\hline Concomitant surgery & $125(41.1)$ & $176(43.7)$ & 0.538 & $108(40.6)$ & $118(44.4)$ & 0.417 \\
\hline Smoker & $131(43.1)$ & $165(40.9)$ & 0.606 & $108(40.6)$ & $115(43.2)$ & 0.595 \\
\hline Abdominal pain & $106(34.9)$ & $149(37.0)$ & 0.568 & $96(36.1)$ & $101(38.0)$ & 0.704 \\
\hline Stroke & $16(5.3)$ & $18(4.5)$ & 0.715 & $11(4.1)$ & $11(4.1)$ & 1.000 \\
\hline Sex, male & $235(77.3)$ & $317(78.7)$ & 0.713 & $207(77.8)$ & $212(79.7)$ & 0.680 \\
\hline Coronary heart disease & $22(7.2)$ & $26(6.5)$ & 0.762 & $20(7.5)$ & $19(7.1)$ & 0.990 \\
\hline Diabetes mellitus & $7(2.3)$ & $8(2.0)$ & 0.779 & $7(2.6)$ & $5(1.9)$ & 0.764 \\
\hline Hypertension & $219(72.0)$ & $293(72.7)$ & 0.860 & $192(72.2)$ & $189(71.1)$ & 0.852 \\
\hline LVEDD, mm & $51.7 \pm 7.44$ & $51.6 \pm 7.32$ & 0.947 & $51.4 \pm 7.36$ & $51.7 \pm 7.62$ & 0.903 \\
\hline $\begin{array}{l}\text { Intraoperative blood loss (mL/ } \\
\mathrm{kg} \text { ) }\end{array}$ & $13.0 \pm 9.42$ & $12.8 \pm 9.67$ & 0.369 & $12.9 \pm 9.73$ & $13.6 \pm 10.9$ & 0.787 \\
\hline Moderate or more PE & $42(13.8)$ & $57(14.1)$ & 0.907 & $34(12.8)$ & 37 (13.9) & 0.799 \\
\hline Moderate or more Al & $112(36.8)$ & $148(36.7)$ & 0.999 & $94(35.3)$ & $96(36.1)$ & 0.925 \\
\hline 30-day postoperative mortality & $15(4.9)$ & $47(11.7)$ & $<0.001$ & $13(4.9)$ & $32(12.0)$ & 0.0025 \\
\hline Estimated long-term mortality & $11.1 \%$ & $19.7 \%$ & $<0.001$ & $7.70 \%$ & $21.1 \%$ & $<0.001$ \\
\hline
\end{tabular}

Data are means \pm SD or number (\%).

$\mathrm{Al}$, aortic regurgitation; $\mathrm{BMI}$, body mass index; $\mathrm{CPB}$, cardiopulmonary bypass; $\mathrm{ED}$, emergency department; $\mathrm{EF}$, ejection fraction; HR, heart rate; LVEDD, left ventricle end-diastolic dimension; PE, pericardial effusion; SBP, systolic blood pressure; WBC, white blood cell.

Two hundred and sixty-six pairs of patients were matched, and all covariates were well balanced (figure 3D). In the matched cohorts, the 30-day postoperative and longterm mortality were significantly higher among patients with preoperative $\mathrm{HR}>80 \mathrm{bpm}$ than among those with $\mathrm{HR} \leq 80 \mathrm{bpm}$ (all, $\mathrm{p}<0.01$ ). Results of the PSM analysis are displayed in table 3. Remarkably, preoperative HR $>80$ bpm was associated with an almost threefold long-term mortality compared with $\mathrm{HR} \leq 80 \mathrm{bpm}$.

Convenient prediction tool for estimated long-term mortality To categorise patients undergoing TAR+FET into different risk zones, we created a risk stratification nomogram (figure 4) based on all the preoperative independent risk factors (HR, age, RI and $\mathrm{EF}$ ). We were able to calculate the probability of long-term mortality in patients undergoing TAR+FET with given values of HR, age, RI and EF. The AUC of the nomogram was $0.72(95 \%$ CI 0.67 to 0.77 ).

\section{Recalculation of 30-day postoperative mortality}

To further consolidate our findings, we recalculated the results above with 30-day postoperative mortality, and found that our results remained stable (online supplemental table 2). In addition, to minimise the bias caused by the 39 patients who failed to undergo follow-up, we inputted their data as either long-term mortality or longterm survival, and the results were similar. Univariable 


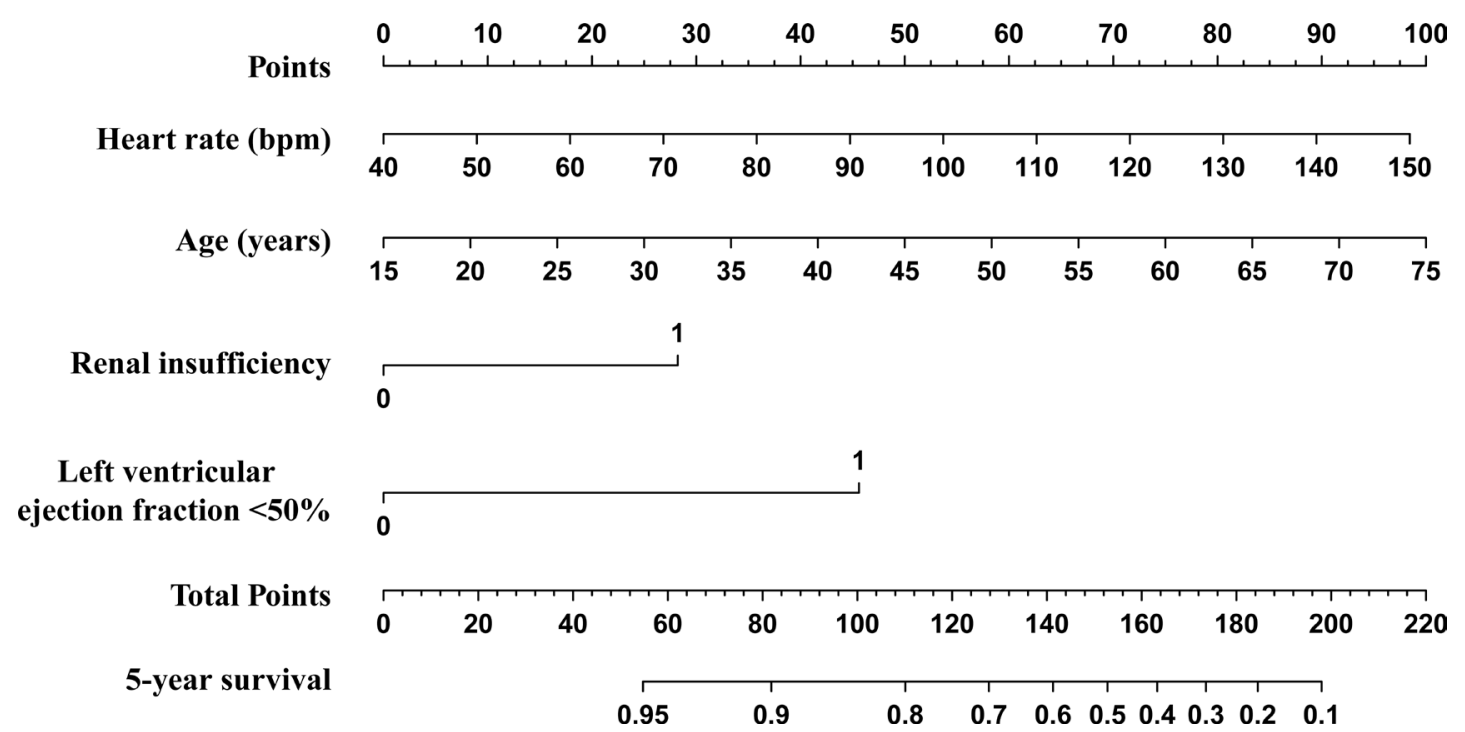

Figure 4 Nomogram for long-term mortality. We can calculate the probability of long-term mortality in patients undergoing $\mathrm{TAR}+\mathrm{FET}$ with given values of HR, age, RI and EF. bpm, beats/min; EF, left ventricular ejection fraction; HR, heart rate; RI, renal insufficiency; TAR+FET, total arch replacement combined with the frozen elephant trunk.

and multivariable Cox regression analyses of long-term mortality showed similar results.

\section{DISCUSSION}

Our study is the first to systematically evaluate the association between HR and long-term mortality, and we found a cut-off $\mathrm{HR}$ and established a convenient predictive model of long-term mortality in patients with ATAAD who underwent TAR+FET. We also used comprehensive methods to further consolidate our findings.

In this study, we demonstrated that HR is an influential independent risk factor for long-term mortality in patients who underwent TAR+FET, and higher HR is associated with significantly increased long-term mortality. These findings are in agreement with those of Zhang et al's ${ }^{18}$ study that analysed 360 patients with acute aortic dissection and found that patients with slower HR had a higher in-hospital survival rate, although this was not statistically significant $(p=0.064)$. Similarly, Suzuki et $a l^{19}$ analysed 1301 patients with acute aortic dissection by analysing the International Registry of Acute Aortic Dissection global registry database and showed that the use of beta-blockers was associated with improved outcomes in both type A and type B aortic dissection patients. This finding supports our results. Importantly, we detected that a cut-off $\mathrm{HR}$ of $80 \mathrm{bpm}$ was associated with a sharp increase in long-term mortality. Long-term mortality was almost threefold greater in patients with $\mathrm{HR}>80 \mathrm{bpm}$ than in those with $\mathrm{HR} \leq 80 \mathrm{bpm}$. Therefore, HR > 80 bpm may be considered as an independent risk factor in patients with ATAAD undergoing TAR+FET.

Aggressive medical treatment of aortic dissection was first advocated in the $1960 \mathrm{~s} .{ }^{20}$ The authors established the reduction of SBP and diminution of the rate of left ventricular ejection $(\mathrm{dP} / \mathrm{dt})$ as the two primary goals of pharmacological therapy. According to previous studies, ${ }^{21}$ when HR decreases, both blood pressure and left ventricular $\mathrm{dP} / \mathrm{dt}$ decrease. This may be the main reason that slower HR is associated with improved longterm mortality in patients with ATAAD. Besides, HR has been reported in association with the prognoses of various diseases. ${ }^{22}$ One study ${ }^{23}$ enrolled 112680 subjects in 12 cohort studies and reported a continuous, increasing association between having a rest HR above approximately $65 \mathrm{bpm}$ and the risk of both cardiovascular and all-cause mortalities. Similarly, Wang et at analysed 92562 participants in the Kailuan Study and demonstrated that elevated HR was independently associated with an increased risk of myocardial infarction and all-cause death. These large clinical investigations may help explain the benefit of a slower HR in our study from another viewpoint. It is generally believed that a faster HR is beneficial in severe aortic regurgitation (AR), as it potentially shortens the diastolic period during which AR occurs. In our study, 260 patients had moderate to severe AR but we did not find a significant association between preoperative $\mathrm{HR}$ and long-term mortality in patients with AR. This result was in line with that of Yang et al's ${ }^{1}$ study that investigated 820 patients with moderate to severe AR; they demonstrated a robust association between increased $\mathrm{HR}$ and elevated allcause death, which was independent of demographics, comorbidities, guideline-based surgical triggers, the presence of hypertension and use of medications. Similarly, Sampat et $a l^{24}$ conducted an observational study that included 756 consecutive patients with severe AR and found that beta-blocker therapy was an independent predictor of better survival for patients with higher HR.

In previous studies and guidelines, ${ }^{9} 1225$ blood pressure control was one of the main medical treatments 
in patients with aortic dissection. However, this study failed to demonstrate a significant relationship between blood pressure and long-term mortality. Because this study only included patients who underwent TAR+FET, we could not determine the effects of blood pressure on preoperative time. Indeed, many patients in our study received treatment for blood pressure control, and we defined blood pressure as the higher values between radial and dorsalis pedis pressures. In our study, patients had higher blood pressure than previous studies, ${ }^{25}$ and patients with an SBP $\leq 100 \mathrm{~mm} \mathrm{Hg}$ only accounted for $8.77 \%$ (62 cases). These differences might have caused different outcomes.

We did not include intraoperative risk factors in the development of predictive models because we wanted to determine the probability of long-term mortality in patients undergoing TAR+FET before the operation started.

In this study, we failed to find a significant relationship between HR in emergency department and long-term mortality. Therefore, we suggest that a patient can benefit from HR reduction if HR could be controlled to lower than $80 \mathrm{bpm}$ no matter how the HR was when a patient arrived in emergency department.

\section{Limitations}

This study has several limitations. First, the retrospective and observational nature of the study might have caused bias. To reduce selection bias, only one type of surgery $(\mathrm{TAR}+\mathrm{FET})$ was chosen in this study and a PSM approach was used. Second, by design, we could not include patients who did not undergo surgery or died before arriving in operating room. Finally, this was an observational study, patients did not receive the same preoperative treatment, thereby we did not take preoperative medication into consideration. Prospective randomised trials are needed to reveal the association between preoperative control of HR and patients' outcomes to reduce long-term mortality in this population.

\section{CONCLUSIONS}

HR is a powerful predictor of long-term mortality and HR $>80 \mathrm{bpm}$ is associated with significantly increased long-term mortality for patients with ATAAD undergoing TAR+FET. We recommend combining HR, age, RI and $\mathrm{EF}$ to predict long-term mortality in patients undergoing TAR+FEF.

\footnotetext{
Author affiliations

${ }^{1}$ Anaesthesiology, Chinese Academy of Medical Sciences \& Peking Union Medical College Fuwai Hospital, Xicheng District, Beijing, China

${ }^{2}$ Pain Medicine, Peking University Third Hospital, Beijing, China

${ }^{3}$ Cardiology, Peking Union Medical College Hospital, Dongcheng District, Beijing, China

${ }^{4}$ Medical Research and Biometrics Center, National Centre for Cardiovascular Diseases, Chinese Academy of Medical Sciences and Peking Union Medical College, Beijing, Beijing, China

${ }^{5}$ Cardiovascular Surgery, Chinese Academy of Medical Sciences \& Peking Union Medical College Fuwai Hospital, Xicheng District, Beijing, China
}

Contributors YZ, QL and XG had full access to all the data in the study and are responsible for the integrity of the data and the accuracy of the data analysis. Study concept and design: YZ, QL, XG, CY, SY. Acquisition of data: YZ, YJ, HW, LC, FY. Analysis and interpretation of the data: YZ, QL, YW, SY. Drafting of the manuscript: YZ. Revision of the manuscript for important intellectual content: all authors. Su Yuan is responsible for the overall content as the guarantor.

Funding This work was supported by CAMS Innovation Fund for Medical Sciences (CIFMS) (No. 2018-I2M-1-001) and the National Natural Science Foundation of China (81500306).

Competing interests None declared.

Patient consent for publication Not applicable.

Ethics approval This study was approved by the Ethics Committees of Fuwai Hospital in Beijing, China (2017-877).

Provenance and peer review Not commissioned; externally peer reviewed.

Data availability statement No data are available.

Supplemental material This content has been supplied by the author(s). It has not been vetted by BMJ Publishing Group Limited (BMJ) and may not have been peer-reviewed. Any opinions or recommendations discussed are solely those of the author(s) and are not endorsed by BMJ. BMJ disclaims all liability and responsibility arising from any reliance placed on the content. Where the content includes any translated material, BMJ does not warrant the accuracy and reliability of the translations (including but not limited to local regulations, clinical guidelines, terminology, drug names and drug dosages), and is not responsible for any error and/or omissions arising from translation and adaptation or otherwise.

Open access This is an open access article distributed in accordance with the Creative Commons Attribution Non Commercial (CC BY-NC 4.0) license, which permits others to distribute, remix, adapt, build upon this work non-commercially, and license their derivative works on different terms, provided the original work is properly cited, appropriate credit is given, any changes made indicated, and the use is non-commercial. See: http://creativecommons.org/licenses/by-nc/4.0/.

ORCID iD

Su Yuan http://orcid.org/0000-0003-3924-7548

\section{REFERENCES}

1 Yang L-T, Pellikka PA, Enriquez-Sarano M, et al. Diastolic blood pressure and heart rate are independently associated with mortality in chronic aortic regurgitation. J Am Coll Cardiol 2020;75:29-39.

2 Lonn EM, Rambihar S, Gao P, et al. Heart rate is associated with increased risk of major cardiovascular events, cardiovascular and all-cause death in patients with stable chronic cardiovascular disease: an analysis of ONTARGET/TRANSCEND. Clin Res Cardiol 2014;103:149-59.

3 Erdur H, Scheitz JF, Grittner U, et al. Heart rate on admission independently predicts in-hospital mortality in acute ischemic stroke patients. Int J Cardiol 2014;176:206-10.

4 Wang A, Chen S, Wang C, et al. Resting heart rate and risk of cardiovascular diseases and all-cause death: the Kailuan study. PLoS One 2014;9:e110985.

5 Opdahl A, Ambale Venkatesh B, Fernandes VRS, et al. Resting heart rate as predictor for left ventricular dysfunction and heart failure: MESA (multi-ethnic study of atherosclerosis). J Am Coll Cardiol 2014;63:1182-9.

6 Kodama K, Nishigami K, Sakamoto T, et al. Tight heart rate control reduces secondary adverse events in patients with type $B$ acute aortic dissection. Circulation 2008;118:S167-70.

7 Kumar KU, Zhao Q, Bai X, et al. Controlled heart rate and blood pressure reduce the life threatening aortic events and increase survival in patients with type B aortic dissection: a single center experience. Int J Cardiol Heart Vasc 2015;8:73-4.

8 Tadros RO, Tang GHL, Barnes HJ, et al. Optimal treatment of uncomplicated type B aortic dissection: JACC review topic of the week. J Am Coll Cardiol 2019;74:1494-504.

9 Hiratzka LF, Bakris GL, Beckman JA. ACCF/AHA/AATS/ACR/ ASA/SCA/SCAI/SIR/STS/SVM guidelines for the diagnosis and management of patients with thoracic aortic disease. Circulation 2010;2010:e266-369.

10 JCS Joint Working Group. Guidelines for diagnosis and treatment of aortic aneurysm and aortic dissection (JCS 2011): digest version. Circ J 2013;77:789-828. 
11 Boodhwani M, Andelfinger G, Leipsic J, et al. Canadian cardiovascular Society position statement on the management of thoracic aortic disease. Can J Cardiol 2014;30:577-89.

12 Erbel R, Aboyans V, Boileau C. ESC guidelines on the diagnosis and treatment of aortic diseases. Eur Heart J 2014;2014:2873-926.

13 Tsai TT, Nienaber CA, Eagle KA. Acute aortic syndromes. Circulation 2005:112:3802-13.

14 Nienaber CA, Powell JT. Management of acute aortic syndromes. Eur Heart J 2012;33:26-35.

15 Evangelista A, Mukherjee D, Mehta RH, et al. Acute intramural hematoma of the aorta: a mystery in evolution. Circulation 2005;111:1063-70.

16 WG M, Zheng J, Dong SB. Sun's procedure of total arch replacement using a tetrafurcated graft with stented elephant trunk implantation: analysis of early outcome in 398 patients with acute type A aortic dissection. Ann Cardiothorac Surg 2013;2:642-8.

17 Levey AS, Stevens LA, Schmid CH, et al. A new equation to estimate glomerular filtration rate. Ann Intern Med 2009;150:604-12.

18 Zhang J, Jiang Y, Gao C, et al. Risk factors for hospital death in patients with acute aortic dissection. Heart Lung Circ 2015;24:348-53.
19 Suzuki T, Isselbacher EM, Nienaber CA, et al. Type-selective benefits of medications in treatment of acute aortic dissection (from the International Registry of Acute Aortic Dissection [IRAD]). Am J Cardiol 2012:109:122-7.

20 Austen WG, DeSanctis RW. Dissecting aneurysm. Surg Clin North Am 1966;46:573-86.

21 Markert M, Trautmann T, Groß M, et al. Evaluation of a method to correct the contractility index LVdP/dt(max) for changes in heart rate. J Pharmacol Toxicol Methods 2012;66:98-105.

22 Tadic M, Cuspidi C, Grassi G. Heart rate as a predictor of cardiovascular risk. Eur J Clin Invest 2018;48:e12892.

23 Woodward M, Webster R, Murakami Y, et al. The association between resting heart rate, cardiovascular disease and mortality: evidence from 112,680 men and women in 12 cohorts. Eur J Prev Cardiol 2014;21:719-26.

24 Sampat U, Varadarajan P, Turk R, et al. Effect of beta-blocker therapy on survival in patients with severe aortic regurgitation results from a cohort of 756 patients. J Am Coll Cardiol 2009;54:452-7.

25 Bossone E, Gorla R, LaBounty TM, et al. Presenting systolic blood pressure and outcomes in patients with acute aortic dissection. J Am Coll Cardiol 2018;71:1432-40. 